\title{
Treatment with D3 Removes Amyloid Deposits, Reduces Inflammation, and Improves Cognition in Aged A $\beta P P / P S 1$ Double Transgenic Mice
}

\author{
Thomas van Groen ${ }^{\mathrm{a}, \mathrm{b}, *}$, Inga Kadish ${ }^{\mathrm{a}}$, Susanne Aileen Funke ${ }^{\mathrm{c}}$, Dirk Bartnik ${ }^{\mathrm{c}}$ and Dieter Willbold ${ }^{\mathrm{c}, \mathrm{d}}$ \\ ${ }^{a}$ Department of Cell, Developmental and Integrative Biology, University of Alabama at Birmingham, \\ Birmingham, AL, USA \\ ${ }^{\mathrm{b}}$ Department of Neurobiology, University of Alabama at Birmingham, Birmingham, AL, USA \\ ${ }^{\mathrm{c}}$ Forschungszentrum Jülich, ICS-6, Jülich, Germany \\ ${ }^{\mathrm{d}}$ Heinrich-Heine-Universität Düsseldorf, Institut für Physikalische Biologie and BMFZ, Düsseldorf, Germany
}

\begin{abstract}
One of the characteristic pathological hallmarks of Alzheimer's disease (AD) is neuritic plaques. The sequence of events leading to deposition of amyloid- $\beta(A \beta)$ peptides in plaques is not clear. Here we investigate the effects of $D 3$, an $A \beta$ oligomer directed $\mathrm{D}$-enantiomeric peptide that was obtained from a mirror image phage display selection against monomeric or small oligomeric forms of $A \beta_{42}$, on $A \beta$ deposition in aged $A \beta P P / P S 1$ double transgenic AD-model mice. Using Alzet minipumps, we infused the brains of these AD model mice for 8 weeks with FITC-labeled D3, and examined the subsequent changes in pathology and cognitive deficits. Initial cognitive deficits are similar comparing control and D3-FITC-treated mice, but the treated mice show a significant improvement on the last day of testing. Further, we show that there is a substantial reduction in the amount of amyloid deposits in the animals treated with D3-FITC, compared to the control mice. Finally, the amount of activated microglia and astrocytes surrounding $A \beta$ deposits is dramatically reduced in the D3-FITC-treated mice. Our findings demonstrate that treatments with the high affinity $\mathrm{A} \beta_{42}$ oligomer binding D-enantiomeric peptide D3 significantly decrease $A \beta$ deposits and the associated inflammatory response, and improve cognition even when applied only at late stages and high age. Together, this suggests that the treatment reduces the level of A $\beta$ peptide in the brains of A $\beta P P / P S 1$ mice, possibly by increasing $A \beta$ outflow from the brain. In conclusion, treatments with this D-peptide have great potential to be successful in AD patients.
\end{abstract}

Keywords: Age, Alzheimer's disease, amyloid, limbic system, mouse, plaques, treatment

\section{INTRODUCTION}

Alzheimer's disease (AD), a progressive neurodegenerative disorder, is associated with several risk factors, including age and inheritance, i.e., genes and

*Correspondence to: Thomas van Groen, Department of Cell Biology, University of Alabama at Birmingham, 1900 University Blvd. THT 912, Birmingham, AL 35294, USA. Tel.: +1 205 9345940; E-mail: vangroen@uab.edu. epigenetics. The majority of AD cases are late onset, lack an obvious genetic etiology, and are characterized as sporadic, whereas only a very small percentage of the cases are early in onset and segregates strongly within families. Most of the early-onset cases of $\mathrm{AD}$ are inherited as autosomal dominant disorders caused by mutations in either the presenilin 1 (PS1) gene on chromosome 14, the presenilin 2 (PS2) gene on chromosome 1 , or the amyloid- $\beta$ protein precursor (A $\beta P P)$ gene on chromosome 21 (e.g., [1]). The 
pathology of $\mathrm{AD}$ is characterized by extracellular amyloid- $\beta$ (A $\beta)$ peptide containing plaques, and intracellular neurofibrillary tangles consisting of aggregated, hyperphosphorylated tau protein [2].

Plaques are primarily made up of $A \beta_{42}[3,4] . A \beta$ is a 39-43 amino acid [5] peptide derived from the proteolytic processing of the A $\beta P P$ (e.g., $[5,6])$. When $\mathrm{A} \beta \mathrm{PP}$ is sequentially cleaved by the $\beta$-secretase and the $\gamma$-secretase, the resulting cleavage product is $A \beta$; in contrast, cleavage by $\alpha$-secretase does not lead to $\mathrm{A} \beta$ production [6]. Most mutations in A $\beta P P$ and PS1 (and PS2) alter A $\beta P P$ metabolism such that there is an increased production of $A \beta$ (especially the longer, fibrillogenic $\left.A \beta_{42}[1,6,7]\right)$. Furthermore, it has been shown that duplication of the A $\beta P P$ gene leads to early onset AD [8-10]. Finally, it has also been shown that variations in the promoter region of the A $\beta P P$ gene affect the risk of AD [11]. Together this implies a central role for aberrant $A \beta P P$ processing in the series of pathological changes occurring during $\mathrm{AD}$, characterized by the appearance of the typical neuritic plaques of AD.

Transgenic ( $\mathrm{Tg}$ ) mice expressing mutated human AD genes offer a powerful model to study the role of $\mathrm{A} \beta$ in the development of AD pathology (e.g., [12]). The present study employs $\mathrm{Tg}$ mice expressing both the human A $\beta P P s w e$ and PS1 $\triangle \mathrm{E} 9$ mutations [13]. These mice develop elevated levels of $A \beta_{42}$ at about four months of age, and around 5 months of age, they show $A \beta$ plaques $[13,14]$. Furthermore, it has been shown that these mice develop cognitive deficits at the age that $A \beta$ pathology appears, i.e., at 6 months of age, with increasing memory deficits at later ages $[15,16]$.

Most likely, amyloid deposition in the brain is caused by an imbalance between $A \beta$ production and $A \beta$ clearance. Even a small imbalance will lead, over the years, to a significantly increased $A \beta$ load in the brain, especially in animals that have a long lifespan and humans. Several mechanisms have been proposed for the clearance of $A \beta$, receptor-mediated $A \beta$ transport across the blood-brain barrier and enzymemediated degradation of the peptide [17, 18]. A possible therapeutic invention that has been proposed is interference in the accumulation and deposition of the $A \beta$ protein in aggregates $[19,20]$. We have developed a series of D-enantiomeric peptides, using mirror-image phage display techniques, that bind $A \beta$, with a preference for $A \beta_{42}$ [21-26]. We have demonstrated that the small D-enantiomeric peptide D3 (D3-FITC) that specifically precipitates oligomers in a mixture containing monomers and oligomers of $A \beta_{42}$ [27] reduces amyloid deposition and decrease cognitive deficits in young Tg AD model mice when they are infused intracerebrally or treated by oral administration [26, 28, 29]. In this study we used Alzet minipumps to infuse the hippocampus of old Tg AD model mice for 8 weeks with the FITC-labeled version of D3. We examined cognitive deficits in the last two weeks of treatment, and $A \beta$ deposits in hippocampus and cortex following sacrifice after the final behavioral testing (i.e., at the end of the eighth week of treatment). The data demonstrate that infusion with the D3-FITC peptide leads to a reduction in the size and number of $\mathrm{A} \beta$ deposits in the hippocampus (and nearby neocortex), whereas the infusion with the vehicle solution does not change $A \beta$ deposits. Similarly, the amount of inflammation (i.e., activated astrocytes and microglia) was significantly reduced in the D3-FITC treated mice. The eight week infusion of the peptide also leads to a small, but significant, improvement in one cognitive measure in these old Tg AD model mice.

\section{MATERIALS AND METHODS}

\section{Animals}

Old male A $\beta P P$ and PS1 double Tg mice (A $\beta$ PPswe/PS1 $\Delta \mathrm{E} 9$ mice, $n=11$ ) [13] were used in the present study. The mice were a kind gift of Dr. S. Handattu; until the treatments, the animals were housed $4 /$ cage in our facility, in a controlled environment (temperature $22^{\circ} \mathrm{C}$, humidity $50-60 \%$, light from $07: 00-19: 00$ ), food and water were available ad libitum. Following the implantation of the Alzet minipump, the animals were housed individually. The experiments were conducted according with the local Institutional Animal Care and Use Committee (IACUC) guidelines.

\section{Peptides}

The identification of D3 is described elsewhere [24-27]. We chose to use D3-FITC (i.e., D3 conjugated with a FITC moiety via an additional C-terminal lysine; D3 sequence: rprtrlhthrnr) because we wanted to follow its fate in the animal and the FITC-label does, if at all, positively affect the D3 A $\beta$ binding properties [30].

\section{Hippocampal infusion}

In two groups of twenty-one months old mice, we unilaterally infused the hippocampus for eight weeks 
using Alzet osmotic minipumps, one group (control group; $n=5$ ) with saline, one group with the D3-FITC dissolved in saline (D3-FITC group; $n=6$ ). The peptide concentration was $0.25 \mathrm{mg} / \mathrm{pump}$, i.e., $0.25 \mathrm{mg}$ in $250 \mu \mathrm{l}$. The Alzet minipump (model \#2004; delivery rate: $0.25 \mu \mathrm{l} / \mathrm{h}$; duration 4 weeks: Alzet) was soaked in sterile saline for $24 \mathrm{~h}$ prior to implantation; the next day the pump, the connecting tube, and cannula (Alzet Brain Infusion Kit 3; Alzet) were filled with the appropriate solution, and were connected, such that no air bubbles were present. Finally, the cannula were implanted in the brain (right dorsal hippocampus); in short, mice were anesthetized, placed in a stereotaxic frame, a hole was drilled above the right dorsal hippocampus, and the cannula was lowered into the hippocampus (coordinates: A-2, L-1.5, V-2.2; [31]). After four weeks the pumps were replaced by new pumps filled with the appropriate solution. Six and a half weeks after the start of the infusion the animals were tested in the water maze; seven and a half weeks after the implantations the animals were tested in the Barnes maze, and then sacrificed for histopathological analysis (see below).

\section{Behavior}

The animals were tested for one week in an open field water maze. Our version of the maze consists of a blue circular tank of clear water $\left(23 \pm 1^{\circ} \mathrm{C}\right)$. The mice are placed in the water at the edge of the pool and allowed to swim in order to locate a hidden, but fixed escape platform, using extramaze cues. On day 1 , the mice are placed in the pool and allowed to swim freely for $90 \mathrm{~s}$ to find the hidden platform (or until they find the hidden platform); each animal is tested for four trials per day. A maximum swim time per trial of $90 \mathrm{~s}$ is allowed; if the animal does not locate the platform in that time, it is placed upon it by the experimenter and left there for $10 \mathrm{~s}$. The inter-trial interval is $120 \mathrm{~s}$.

Each start position (east, north, south, and west) is used equally in a pseudo random order and the animals are always placed in the water facing the wall. All four possible quadrant positions for the platform locations are equally used among all of the animals. The platform is placed in the middle of one of the quadrants of the pool (i.e., northwest, southwest, northeast, or southeast; approximately $30 \mathrm{~cm}$ from the side of the pool). The mouse's task throughout the experiment is to find, and escape on to, the platform. Once the mouse has learned the task (day 5, trial 20), a probe trial is given immediately following the last trial of acquisition on day 5. In the probe trial (i.e., trial 21), the platform is removed from the pool and animals are allowed to swim for $60 \mathrm{~s}$.

The Barnes maze that is used has a design similar to the one developed by Barnes et al. [32] for rats and that has been adapted to the mouse. The raised $(120 \mathrm{~cm}$ above the floor), round platform has a diameter of $140 \mathrm{~cm}$, the escape holes are distributed along the rim of the platform (Columbus Instruments), and the maze is positioned in a brightly lit room. Only one of them, the correct escape hole, has the escape cage attached under it. The mice are trained to escape from the open platform (the start position is in the middle of the platform) to the escape cage. An entry into an incorrect hole is deemed a reference memory error, and an entry into a hole where it was before is a working memory error. The mice are removed from the maze after escaping or after $4 \mathrm{~min}$ has passed, whichever comes first. An entry is defined as the head entering the escape hole. Learning of the task is evaluated by recording the latency to find the correct escape hole, the path length, and percentage of trials each animal finds the correct hole. Four trials are run per day; the learning of the maze takes an average of 5 days. After each testing day, the apparatus is wiped down with chlorhexidine and $70 \%$ ethanol and allowed to air-dry.

\section{Histopathology}

In short, mice were anesthetized and transcardially perfused. Then the brains were removed and cut in half, and the right hemisphere was dropped in $4 \%$ paraformaldehyde. The left hemisphere was divided into four parts (rostral and caudal cortex, hippocampus, and non-cortex) and frozen and stored at $-80^{\circ} \mathrm{C}$ for western and ELISA analysis. Following postfixation (overnight in the fixative) and cryoprotection (30\% sucrose for $24 \mathrm{~h}$ followed by antifreeze [15\% sucrose and $30 \%$ ethylene glycol in $0.05 \mathrm{M}$ phosphate buffer, $\mathrm{pH} 7.4$ ), six series (1 in 6) of coronal sections were cut through the brain. The first series of sections was mounted unstained; the second and third series were stained immunohistochemically according to published protocols [14]; and the other three series were stored in at $-20^{\circ} \mathrm{C}$ in antifreeze for future analysis. One half of the second series was stained for human $\mathrm{A} \beta$ using the W0-2 antibody (mouse antihuman $A \beta_{4-9 ;} 1: 5000$; [33]), while the other half of the second series was stained for mouse $A \beta$ (rabbit anti-rodent A $\beta ; 1$ : 5000; Covance) [14]. One half of the third series was stained for GFAP (mouse anti-GFAP; $1: 1000$; Sigma), whereas the other half was stained for CD11b (rat anti-mouse CD11b; $1: 10000$; Serotec), a 
marker of microglia. Some of these stained sections were double stained with either Congo red, thioflavine $\mathrm{S}$, or thiazine red. A few sections were stained for cathepsin D (goat anti-cathepsin D; 1: 1000; Santa Cruz), a marker of lysosomes. The sections destined for $A \beta$ staining were pretreated for $30 \mathrm{~min}$ with hot $\left(85^{\circ} \mathrm{C}\right)$ citrate buffer. The series of sections were transferred to a solution containing the primary antibody; this solution consists of TBS with $0.5 \%$ Triton X-100 added (TBS-T). Following incubation in this solution for $18 \mathrm{~h}$ on a shaker table at room temperature $\left(20^{\circ} \mathrm{C}\right)$ in the dark, the sections were rinsed three times in TBS-T and transferred to the solution containing the secondary antibody (goat anti-mouse*biotin, Sigma or sheep antirat Ig*biotin, Serotec). After $2 \mathrm{~h}$, the sections were rinsed three times with TBS-T and transferred to a solution containing mouse ExtrAvidin peroxidase (Sigma), following rinsing the sections were incubated for approximately 3 min with Ni-enhanced DAB [34]. In a small number of sections, the $A \beta$ deposits were double labeled for $A \beta_{40}, A \beta_{42}$, GFAP, or CD11b using fluorescent secondary antibodies. All stained and unstained sections (of series 1-3) were mounted on slides and coverslipped.

\section{ELISA}

In short, diluted brain samples (i.e., the hippocampus) were assayed for $A \beta$ in triplicate using the BetaMark X-40 and BetaMark X-42 ELISA kits (Covance), according to the manufacturer's protocol. For the measurement of soluble and insoluble $A \beta$, the mouse brain tissue (the hippocampus) was prepared according to our modification of the manufacturer's protocol [35]. Briefly, the brain tissues were homogenized in an $\mathrm{A} \beta$ extraction buffer containing $20 \mathrm{mM}$ Tris- $\mathrm{HCl}(\mathrm{pH}$ 7.6), $137 \mathrm{mM} \mathrm{NaCl}, 1 \%$ Triton $\mathrm{X}-100,2 \%$ SDS, and protease inhibitors (complete protease inhibitor cocktail, Boehringer Mannheim, Mannheim, Germany), and centrifuged at $100,000 \mathrm{~g}$ for $1 \mathrm{~h}$. Supernatant was collected (SDS soluble) and stored at $-80^{\circ} \mathrm{C}$ until analysis or analyzed immediately. Pellets were dissolved in $70 \%$ formic acid (FA), incubated at room temperature with gentle shaking for $2 \mathrm{~h}$, and then centrifuged at $100,000 \mathrm{~g}$ for $1 \mathrm{~h}$. The supernatants were collected (SDS insoluble). The FA extraction solution was neutralized and diluted 20 times with a neutralizing buffer containing $1 \mathrm{M}$ Tris, $0.5 \mathrm{M} \mathrm{Na}_{2} \mathrm{HPO}_{4}$, and $0.05 \%$ $\mathrm{NaN}_{3}$ before analysis by ELISA. In vivo administered D3 was confirmed not to interfere with the ELISA kit for the analyses of $A \beta$ in the samples from this study (the caudal brain samples were used for this analysis).

\section{Quantification}

The appropriate areas (dorsal hippocampus and midline dorsal and frontal cortices) of the brain were digitized using a Olympus DP70 digital camera [34]. To avoid changes in lighting, which might affect measurements, all images were acquired in one session with a fixed setting for the light level. Further, to avoid differences in staining density between sections, the measurements were performed on sections that were stained simultaneously, i.e., in the same staining tray. The percentage of area covered by the reaction product to $A \beta$ was measured in the hippocampus (and frontal cortex) using the ScionImage (NIH) program $[34,35]$. The threshold for the measurements was set at the appropriate level to avoid measuring background staining, and used for all images. Using a similar procedure, using digital images able to overlay the defined measurement area, plaques were counted in the same brain area on the adjacent sections that were stained with Congo red. The density of GFAP or CD11b staining was measured by placing a standard sized circle (200 $\mu \mathrm{m}$ diameter) around the plaque core (stained with Congo red), and measuring the optical density of the staining in the circle using the ScionImage (NIH) program. All density measurements were done in triplicate, i.e., measuring the standardized area around three plaques at three different levels of the dorsal hippocampus and the frontal, midline cortex. These measurements were done in triplicate in sections (that had been stained simultaneously) by an observer blinded to the treatment of the animal. All data were analyzed by ANOVA (Systat 11; between groups), and post-hoc tests (Tukey and Scheffe) were carried out to determine the source of a significant main effect or interaction. All data are shown with as the average \pm SEM.

\section{RESULTS}

The implantation of the Alzet minipumps and brain cannulas did not change any obvious physiological parameters (e.g., body weight or general health, i.e., the look of fur, posture, and motor activity) in the implanted mice, or cause any noticeable discomfort. None of the animals lost the brain cannula or developed any health or motor problems. One animal turned out to be negative for human $\mathrm{A} \beta \mathrm{PP}$ expression and $\mathrm{A} \beta$ deposits, most likely because it had been incorrectly genotyped.

After six and a half weeks of infusion, the two groups (i.e., control and D3-FITC treated) of A $\beta$ PP/PS1 mice were tested in the water maze. There was no significant 
A

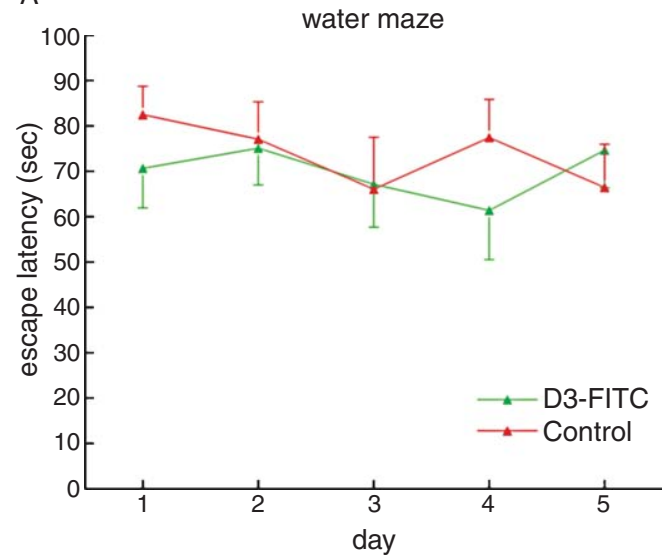

C

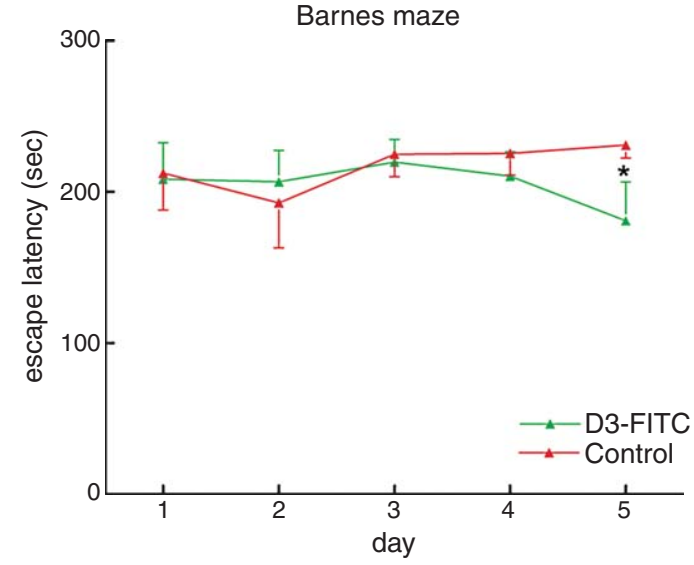

B
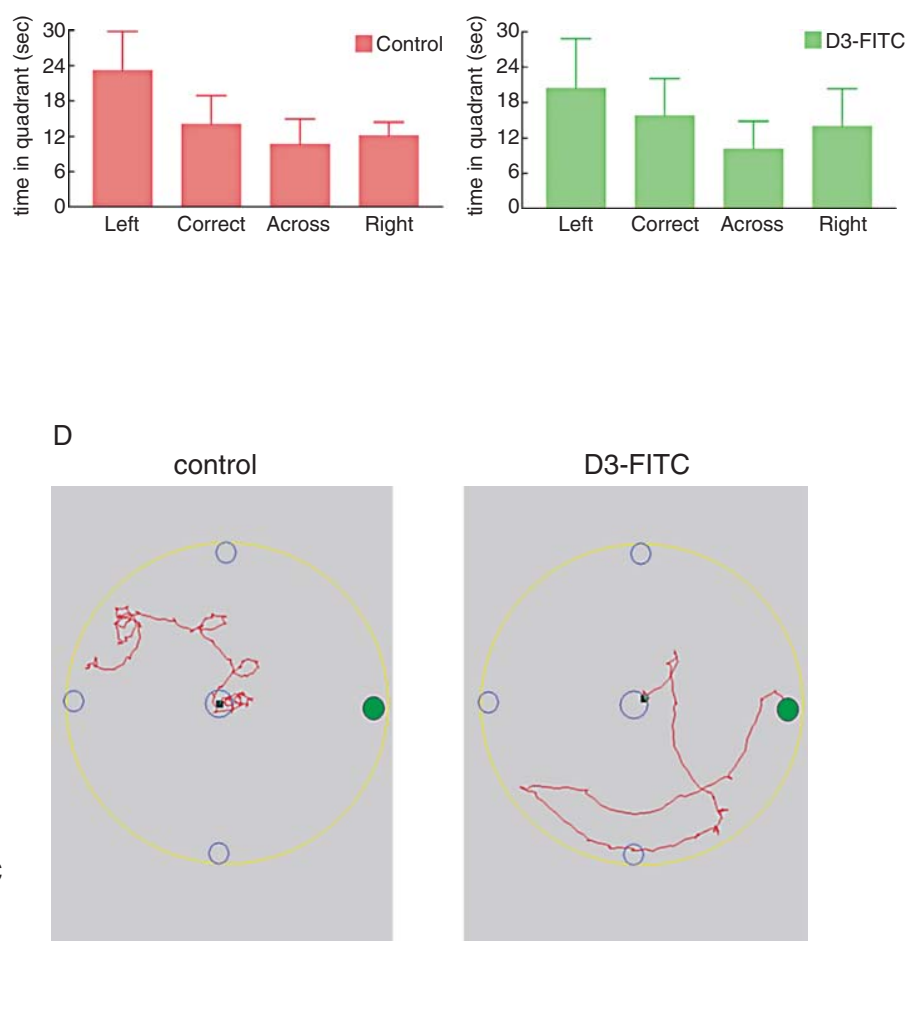

Fig. 1. Three graphs showing the learning curves of the three groups of mice: A) the daily mean performance in the water maze; B) the probe trial performance of the two groups of mice ( $L=$ left, $C=$ correct, $A=$ across, and $R=$ right quadrant); $C$ ) the daily mean performance in the Barnes maze; and D) examples of tracks of a control and a D3-FITC mouse in the Barnes maze. *indicates significantly $(p<0.05)$ different on last day of testing.

difference in the swimming speed between the groups of mice $(14.9 \pm 2.4 \mathrm{~m} / \mathrm{s}$ and $15.3 \pm 2.4 \mathrm{~cm} / \mathrm{s}$, respectively). At the end of the week of training, there was no difference in escape latency between the two groups of mice in water maze performance (Fig. 1A); furthermore, neither of the two groups of mice showed any significant improvement of learning during the week of testing. Moreover, as expected, none of the groups showed a preference for the correct quadrant in the probe trial which followed the last training trial (Fig. 1B). The week following the water maze test, the animals were trained on the Barnes maze. At the end of the week of training, there was a small, but significant, difference in escape latency between the two groups of mice (Fig. 1C), with the D3-FITC group of mice showing a significant improvement of learning at the last day of testing. There was also a significant difference in the number of correct responses on that day, $14 / 20$ (D3-FITC) versus 2/20 (control). There was no significant difference in the average distance the animals moved $(212 \pm 35 \mathrm{~cm}$ and $193 \pm 34 \mathrm{~cm}$, D3-FITC and control, respectively; Fig. 1), but the D3-FITC treated mice had a slightly but not significantly faster average speed of moving $(1.2 \pm 0.3$ versus $0.9 \pm 0.4 \mathrm{~cm} / \mathrm{s}$ ). It should be noted that the difference in average speed was caused by longer periods of nonmoving in the control mice (corrected average speeds: $1.3 \pm 0.3$ and $1.2 \pm 0.4 \mathrm{~cm} / \mathrm{s}$, respectively). Similarly, for both groups, the walking speed in the Barnes maze is much slower than the swimming speed in the water maze. After completion of the behavioral testing, the animals were sacrificed and the brains were assessed for $A \beta$ levels, $A \beta$ load, and $A D$ pathology-related inflammation.

The implantation of the cannula was in the dorsal hippocampus in all animals (Fig. 2). The extent 

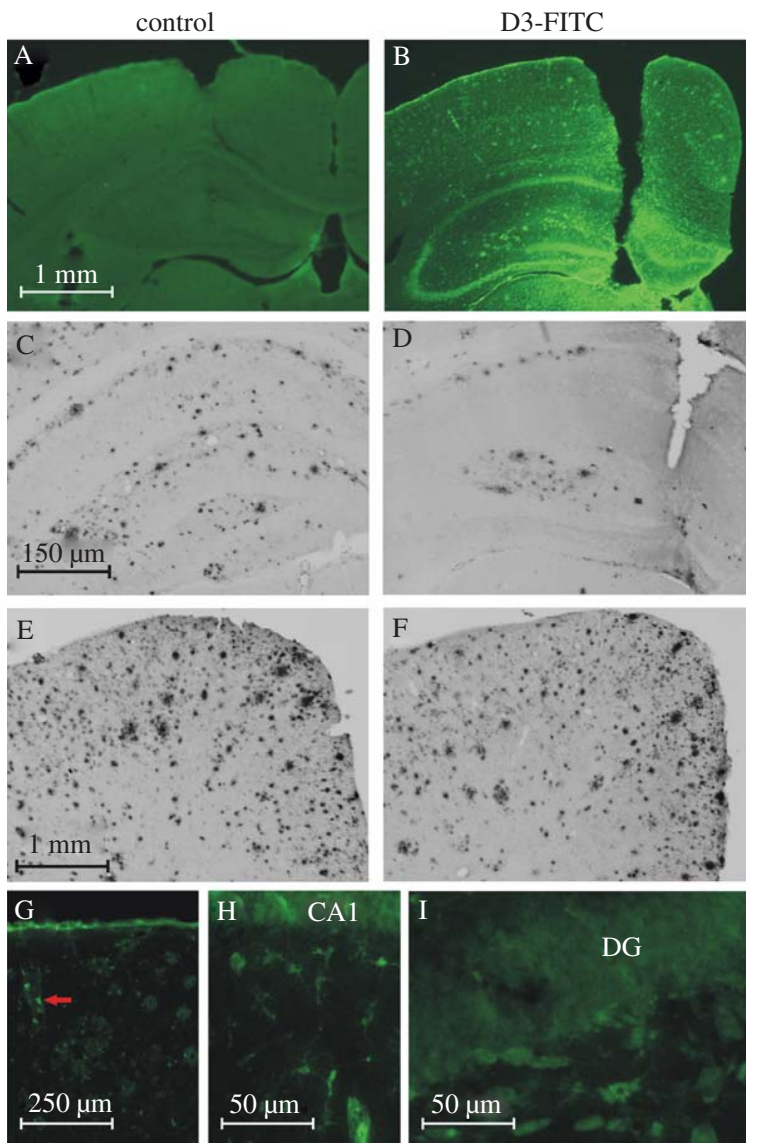

Fig. 2. Two sets of three photomicrographs (A-F) of coronal sections through the dorsal midline cortex and hippocampus of the two groups of $\mathrm{A} \beta \mathrm{PP} / \mathrm{PS} 1$ mice and three high power photmicrographs (G-I). Top row (A, B) unstained sections, lower two rows, sections stained for $A \beta$ (with W0-2), middle row (C, D) hippocampus, and bottom row (E, F) rostral midline cortex. Three high power photomicrographs: G) parietal cortex showing D3-FITC labeled perivascular macrophages (red arrow); $\mathrm{H}$ ) labeled microglia cells in area CA1; and I) labeled neurons in the dentate gyrus. Please note the difference in $A \beta$ staining density in the hippocampus between the treated and non-treated mice.

of the distribution of the infused peptide in the brain could be analyzed in the unstained sections of the brain since the infused D-peptide was conjugated to a FITC molecule. Inspection of brain sections with an epifluorescent microscope revealed that all dense $A \beta$ deposits in the whole brain were FITC-labeled, with a decrease in brightness further from the infusion site (Fig. 3). It should be noted that all plaques, i.e., $A \beta$ deposits with a Congo red positive core and some $A \beta$ deposits in blood vessel walls were labeled, but diffuse $A \beta$ deposits were not labeled by the D3-FITC peptide. As expected, none of the control infused mice showed any D3-FITC-labeled A $\beta$ deposits (Fig. 2A).
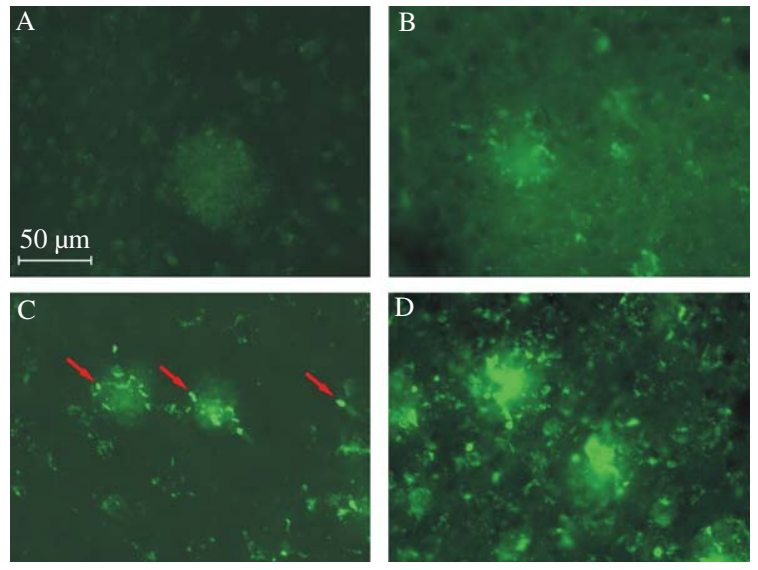

Fig. 3. Four high power photomicrographs (A-D) of coronal sections through the dorsal, midline cortex following long-term infusion of D3-FITC: A) image of labeled plaques $>3 \mathrm{~mm}$ away from the infusion site; B) image of labeled plaques $\sim 1 \mathrm{~mm}$ from the infusion site; C) image showing labeled plaques near the infusion site; and D) labeled plaques at the injection site. Notice the increase in staining density in plaques near the infusion site. Red arrows in $\mathrm{C}$ indicate dystrophic neurites.

It is notable that near the infusion site, but not elsewhere in the brain, many neurons showed signs of having taken up D3-FITC, i.e., they showed intracellular FITC labeling (Fig. 2H, I). Most of the D3-FITC labeling is present on the $A \beta_{42}$ surrounding the dense core of $\mathrm{A} \beta$ plaques (Fig. 3), but some labeling is present in the dystrophic axons surrounding the plaque (Fig. 3). Furthermore, in the D3-FITC infused mice a small number of layer II neurons in the entorhinal cortex (and a few cells in the cholinergic basal forebrain; not illustrated) showed intracellular labeling with D3-FITC, likely due to D3-FITC that was retrogradely transported from the infusion site, i.e., the dorsal hippocampus (not illustrated). It is of interest to note that these neurons showed D3-FITC labeling in lysosomes (confirmed with double labeling with lysosomal marker, cathepsin D). Further, some perivascular macrophages throughout the brain showed labeling with D3-FITC (Figs. 2G and 5A), and it should be noted that these were mainly present on penetrating arterioles. Finally, the D3-FITC peptide had also been taken up by a few microglial cells (Figs. 2H and 5D), and these microglial cells were mainly present surrounding $A \beta$ deposits near the infusion site, but a few microglial cells near the infusion site also showed intracellular labeling with D3-FITC (Fig. 5D). Doublelabeling with GFAP demonstrated that no D3-FITC labeled astrocytes were present anywhere in the brain (not illustrated). 
Table 1

The number of animals per group, body weight, the $A \beta$ load, the number of Congo Red positive plaques, and the density of GFAP and CD11b staining around plaques in the dorsal hippocampus, numbers are average \pm SEM

\begin{tabular}{lcc}
\hline Group & Control & D3-FITC \\
\hline Infusion & Saline & D3-FITC peptide \\
Number & $n=5$ & $n=5$ \\
Body weight & $36.1 \pm 2.5 \mathrm{~g}$ & $37.2 \pm 2.8 \mathrm{~g}$ \\
$\mathrm{~A} \beta$ load - hip & $5.0 \pm 0.4 \%$ & $1.8 \pm 0.3 \% *$ \\
$\mathrm{~A} \beta$ load - cort & $9.8 \pm 0.9 \%$ & $9.0 \pm 1.0 \%$ \\
$\mathrm{~A} \beta_{40}$ insoluble & $201246 \pm 36166 \mathrm{pg} / \mathrm{g}$ & $68264 \pm 1993 \mathrm{pg} / \mathrm{g} *$ \\
$\mathrm{~A} \beta_{40}$ soluble & $11686 \pm 1824 \mathrm{pg} / \mathrm{g}$ & $7403 \pm 499 \mathrm{pg} / \mathrm{g} *$ \\
$\mathrm{~A} \beta_{42}$ insoluble & $495730 \pm 15767 \mathrm{pg} / \mathrm{g}$ & $355922 \pm 9258 \mathrm{pg} / \mathrm{g} *$ \\
$\mathrm{~A} \beta_{42}$ soluble & $174109 \pm 2182 \mathrm{pg} / \mathrm{g}$ & $10416 \pm 2437 \mathrm{pg} / \mathrm{g} *$ \\
Congo Red \# & $157 \pm 17$ & $73 \pm 9^{*}$ \\
GFAP & $102 \pm 2$ & $82 \pm 2^{*}$ \\
CD11b & $159 \pm 3$ & $135 \pm 3^{*}$ \\
\hline
\end{tabular}

*indicates significantly different between control and D3-FITC treated, $p<0.05$.

In the sections that were stained for human $A \beta_{4-10}$, the $A \beta$ load was measured in the hippocampus and dorsal, midline cortex and frontal cortex. In the group infused with D3-FITC there was significant reduction in the $A \beta$ load in the hippocampus and in the dorsal midline cortex, compared to the control-infused mice (Figs. 2C, D; Table 1). In contrast, there was no difference in the $A \beta$ load between the control and the D3-FITC infused mice in brain areas more than $3 \mathrm{~mm}$ away from the infusion site, i.e., in the frontal cortex (Figs. 2E, F; Table 1). The analysis of labeling for mouse $A \beta$ showed a small but significant decrease in mouse $A \beta$ load in the hippocampus in the D3-FITC group compared to the control group.

The $A \beta$ levels were measured in the contralateral (non-infused) hippocampus, and both the levels of the soluble and insoluble $A \beta_{40}$ and $A \beta_{42}$ were significantly reduced in the D3-FITC treated mice compared to the untreated control mice (Fig. 4).

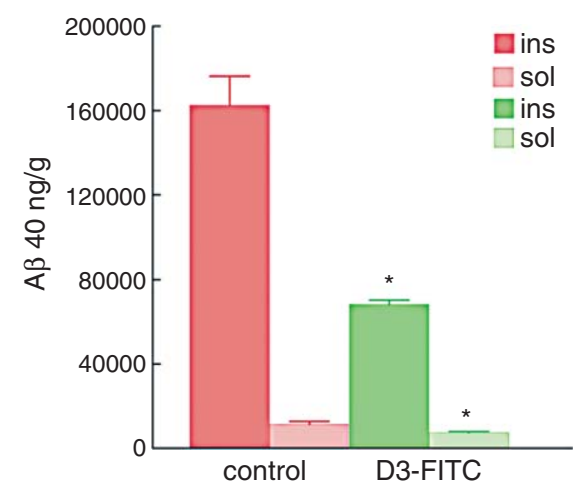

Analysis of the sections that were stained for GFAP or microglia revealed that the implantation of the cannula and the infusions did not cause any significant inflammation (Fig. 6). The only infusionrelated inflammation that was present was around the implanted infusion cannula (not illustrated), and was similar among the two groups of mice. A more detailed analysis of the magnitude of inflammation surrounding $A \beta$ deposits, however, revealed that the D3-FITC treatment significantly reduced the amount of plaquerelated inflammation (measured in both GFAP and CD11b staining) compared to the control brains in the brain area near the infusion site (Fig. 6, Table 1). Double staining for microglia and GFAP confirmed that at D3-FITC labeled plaques both glial cell types were significantly less activated compared to control-infused mice.

\section{DISCUSSION}

In this study we infused the hippocampus of $\mathrm{Tg}$ AD model mice for eight weeks with the small D-enantiomeric peptide D3 conjugated to FITC (D3FITC) that has a high affinity for oligomeric $A \beta_{42}[23$, $24,26]$, and examined cognitive performance after 6.5 weeks, and the $A \beta$ load after the end of the cognitive testing.

One of the two characteristic pathological hallmarks of $\mathrm{AD}$ is the presence of neuritic plaques [36]. These plaques have a dense core of aggregated $A \beta$ peptides (e.g., [3]), which stains with thioflavine-S and Congo red. However, diffuse amyloid deposits have also been shown to be present in AD brains, and they have been shown to be present in AD model mice [14]. In our experiments, all dense plaques were labeled by D3FITC; in contrast, diffuse deposits, i.e., A $\beta$ deposits

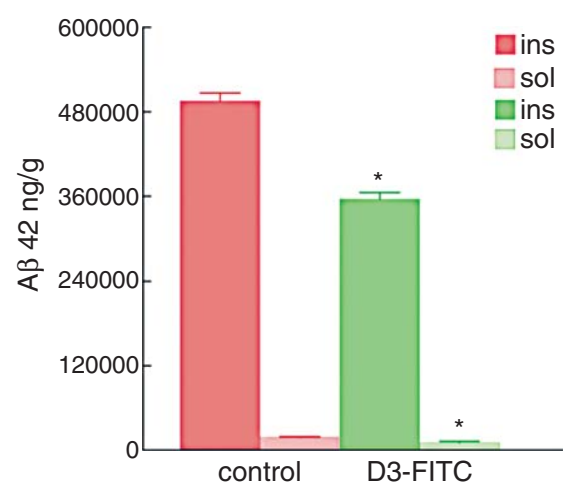

Fig. 4. Two graphs showing the $A \beta_{40}$ and $A \beta_{42}$ levels in the hippocampus. Please note the significant $(* ; p<0.05)$ decrease in both the insoluble and soluble $A \beta_{40}$ and $A \beta_{42}$ levels in the treated mice compared to the control mice. 


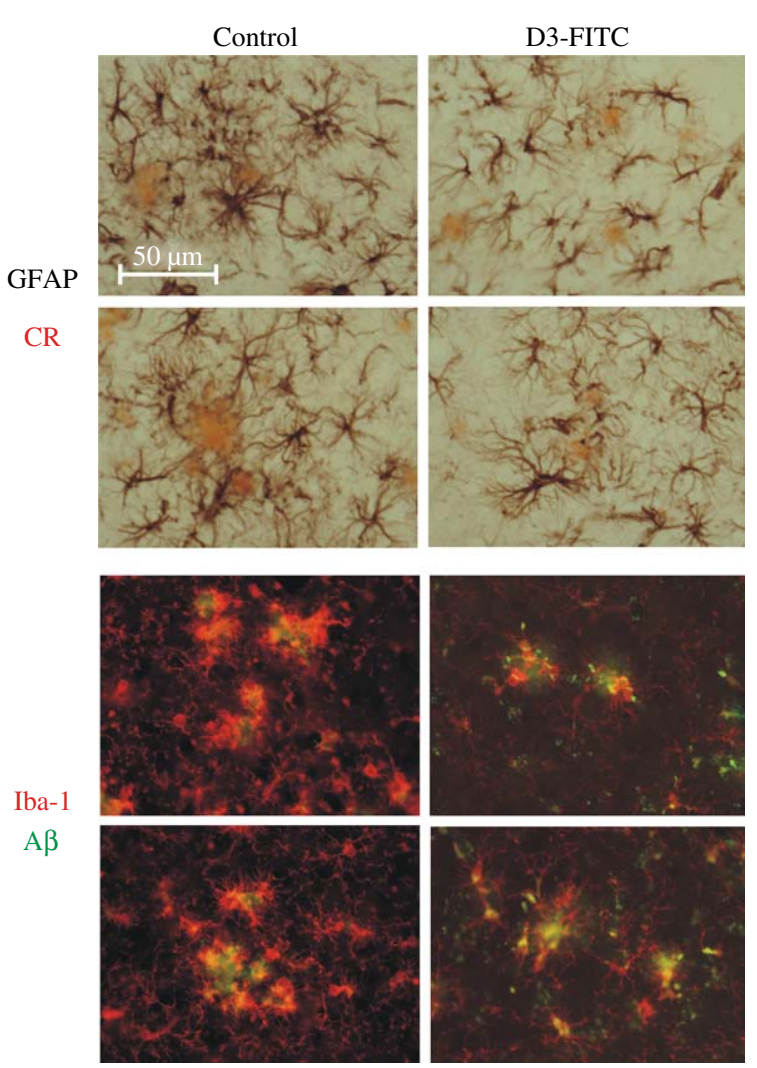

Fig. 5. High power photomicrographs demonstrating plaques in double-labeled coronal sections of the midline cortex, of mice that were control or D3-FITC infused. Top four images, GFAP (i.e., GFAP and Congo red); bottom four images, microglia (i.e., Iba-1 and $\mathrm{A} \beta$ or D3-FITC). Left column control-infused mice, and right column D3-FITC-infused mice. Please note the reduction in the level of inflammation between the two treatments.

without a thioflavine-S positive core, did not show any labeling with the peptide. The diffuse deposits did not show much, if any, labeling with $A \beta_{42}$ specific antibodies [14], which is likely why the D3-FITC did not bind to these deposits. In contrast, some $A \beta$ in blood vessel walls (cerebral amyloid angiopathy) is labeled by D3-FITC. Similarly, D3 did not bind A $\beta$ deposits in blood vessel walls in young mice when they predominantly consist of $A \beta_{40}$ [37], but it should be noted that at the ages when $A \beta_{42}$ is present in these deposits the D3-FITC does label them [28], as D3-FITC also does in these old mice. In agreement with these findings, in earlier in vitro experiments, we have shown that at high ages ( $>15$ months of age) these deposits are labeled by $\mathrm{A} \beta_{42}$ antibodies and with both D1 and D3 [30].

The data from our experiments show that the D3FITC infused mice have a much lower $A \beta$ load in the hippocampus, demonstrating that binding of D3-FITC to oligomeric $A \beta_{42}$ helps in reducing $A \beta$ deposition in the hippocampus and the adjacent neocortex. However, not only is amyloid deposition decreased, existing deposits are also significantly cleared as the typical plaque load of mice at the age, when the treatment started (21 months) is much higher than observed after D3-FITC treatment. This, most likely, is partially brought about by changes in the aggregation properties of the A $\beta_{42}$-D3-FITC complex, compared to the high propensity of $A \beta_{42}$ to aggregate $[38,39]$. This would then lead to a decrease in the $A \beta$ deposition rate, and thus a lesser number and/or smaller plaques [27]. Several studies have shown that the use of $\beta$-sheet breakers [40-42] can reduce $A \beta$ aggregation and $A \beta$ deposition, both in vitro and in vivo. Our data confirm that even treatment with an $\mathrm{A} \beta_{42}$ binding peptide alone (i.e., without attached $\beta$-sheet breaker) will decrease amyloid deposition. Insoluble $A \beta_{1-40}$ is even more reduced after D3-FITC treatment than insoluble $A \beta_{1-42}$, most probably because insoluble $A \beta$ aggregates consist of mixtures of $A \beta_{1-40}$ and $A \beta_{1-42}$ and the higher the $A \beta_{1-40}$ content is, the less stable the aggregates are and the more amenable they are to D3-FITC, even if D3 was reported to bind preferentially $A \beta_{1-42}$. On the other hand, it is also possible that the clearance of the D3-A $\beta_{42}$ complex from the brain has improved compared to the clearance of $A \beta_{42}[18,43,44]$. Several mechanisms have been proposed for the clearance of $\mathrm{A} \beta$, receptor-mediated $A \beta$ transport across the bloodbrain barrier and enzyme-mediated degradation of the peptide $[18,43]$. It is more likely that $A \beta$ transport out of the brain is improved than that $A \beta$ degradation has increased, since the properties of the $A \beta_{42}$-D3FITC complex are possibly not improving enzymatic degradation [45].

All plaques in our AD-model mice are accompanied by activated glial cells, both astrocytes and microglia (e.g., [46-48]). The role of the activated glial cells is unclear: on the one hand they could protect the brain by removing $A \beta$, on the other hand they can secrete inflammatory cytokines and generate nitric oxide, and can thus damage and kill bystander neurons [49]. It should be noted that in this mouse model, no dead or dying neurons are present, even near plaques [47]. The role of activated microglia cells in the uptake of $A \beta$ is disputed, with some groups showing clearance of $A \beta$ by microglia (e.g., [50, 51], whereas others have shown that microglia do not take up $A \beta$ [52]. Similarly, the plaques in all our animals are surrounded by activated glial cells; however, in the D3-FITC infused mice, only microglial cells show fluorescence intracellularly, whereas no D3-FITC is present in any activated astrocyte surrounding the plaque. This indicates that 

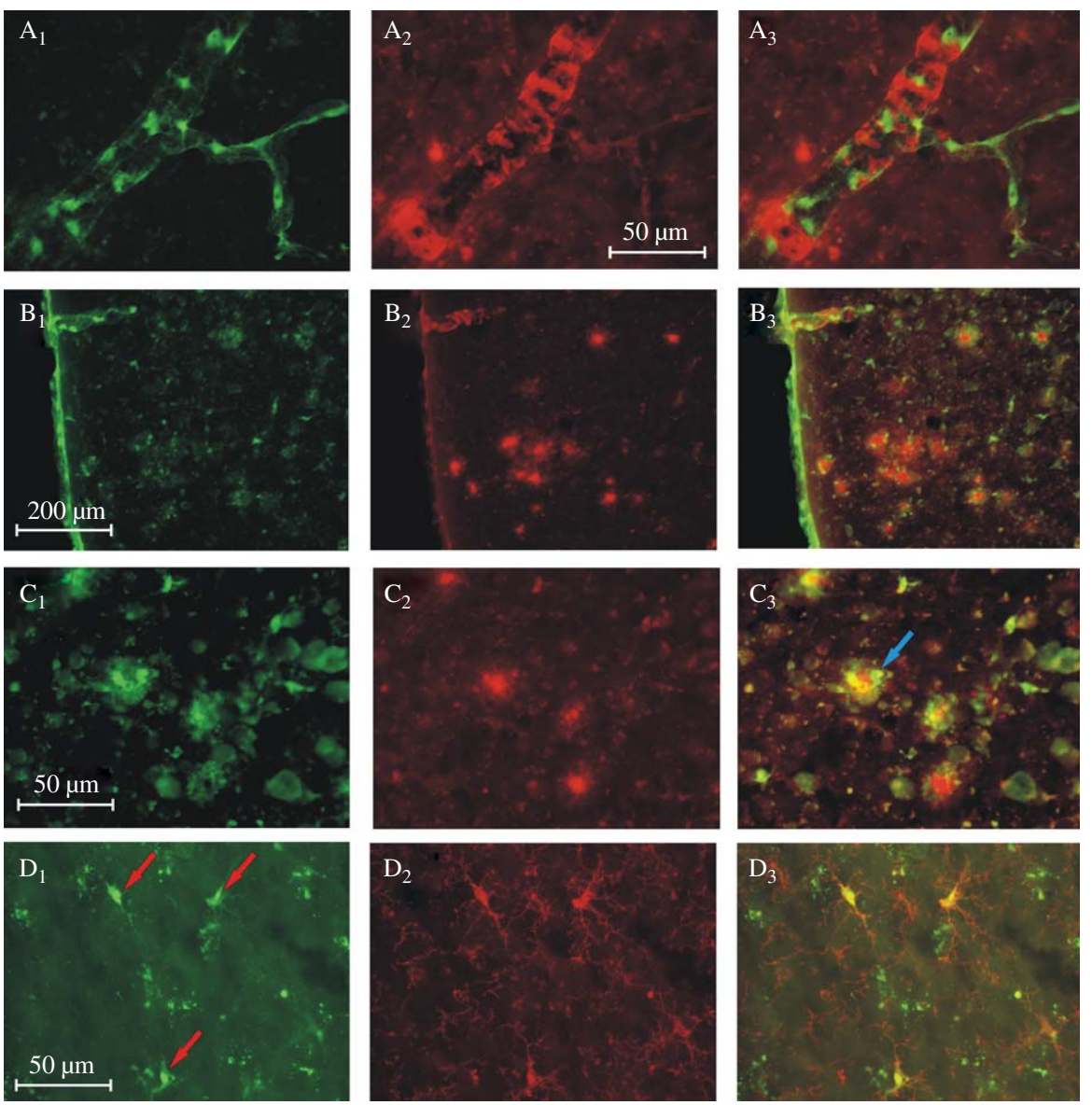

Fig. 6. Four series of photomicrographs of coronal sections through the dorsal midline cortex and hippocampus of the D3-FITC infused A $\beta P P / P S 1$ mice: $A_{1}$ ) unstained section of a blood vessel, note the labeled perivascular macrophages; $A_{2}$ ) the same section stained with Congo red showing $A \beta$ deposition; $A_{3}$ ) combined image; $B_{1}$ ) unstained section of midline cortex, showing D3-FITC labeling; $B_{2}$ ) the same section stained with Congo red showing $A \beta$ deposition; $B_{3}$ ) combined image showing D3-FITC surrounding plaque cores; $C_{1}$ ) unstained section of area CA1; $C_{2}$ ) the same section double stained with Congo red showing $A \beta$ deposition; $C_{3}$ ) combined image showing D3-FITC in labeled dystrophic neurites (blue arrow); $\mathrm{D}_{1}$ ) unstained section of stratum radiatum of area CA1; $\mathrm{D}_{2}$ ) the same section stained red for Iba-1 showing microglial cells; and $\mathrm{D}_{3}$ ) combined image, note the three microglial cells that have taken up D3-FITC (red arrows).

microglial cells do contribute to the reduced $A \beta$ load in the treated mice.

In the D3-FITC infused mice, however, compared to the control infused mice, the dense $A \beta$ deposits are associated with much lower numbers of activated microglia or activated astrocytes. This suggests that the binding of $\mathrm{D} 3$-FITC to deposited $\mathrm{A} \beta_{42}$ changes the structure of $A \beta_{42}$ evoking less inflammatory responses. Furthermore, the size of the $A \beta$ deposits in the hippocampus is smaller in the D3-FITC treated mice. Together, this suggests that the $A \beta$ in the plaques, upon binding to D3-FITC, has changed aggregation kinetics, for instance more amorphous (non-depositing) A $\beta$ aggregates could be formed. Finally, it should be noted that the number of deposits that stain for thioflavine-S or Congo red has also been significantly reduced in the hippocampus. This indicates that either less new deposits were formed during the four weeks of treatment or deposits were removed by microglia. It is not likely that microglial cells have taken up all $A \beta_{42}$-D3-FITC, since little intracellular fluorescence is observed in most microglial cells. On the other hand, clear FITC-fluorescence is present in pericytes/perivascular macrophages $[53,54]$ indicating that these cells have taken up the D3-FITC-A $\beta_{42}$ complex. These cells may have increased the clearance of the complex from the brain through the bloodbrain barrier [44, 53, 54]. In our earlier studies, we have not observed uptake of D3-FITC in microglial cells, indicating that the properties of the microglial cells in these older animals are slightly different, most likely due to the increased age of these mice $[55,56]$. 
Furthermore, we observed uptake of D3-FITC by neurons near the infusion site, most likely by uptake of the Aß42-D3-FITC complex.

It has been suggested that the progression of the pathology in $\mathrm{AD}$ is related to the connections between areas displaying early deposits and the cortical regions showing later pathology, summarized by Hardy ([57]) in the "anatomical cascade hypothesis". Our data showing labeled neurons in layer II of the entorhinal cortex that are most likely due to the retrograde transport of D3-FITC (or the A $\beta_{42}$-D3-FITC complex), confirm that $A \beta$ is retrogradely transported through axons [30]. It should be noted that the neurons in the entorhinal cortex showing intracellular D3-FITC are healthy, and do not show signs of cell death. Furthermore, there is no increased inflammation in the area of these intracellularly labeled neurons.

There was a significant improvement in the cognitive deficits between the control and D3-FITC treated mice in the Barnes maze task, but not in the water maze task. The performance of the two groups of mice in the water maze is quite similar to earlier reports $[35,58]$, i.e., these $\mathrm{Tg} \mathrm{AD}$ model mice are significantly impaired in their water maze performance at 12 months of age, and even more impaired at this age ( 22 months of age). At the end of the first week of training, neither control nor D3-FITC infused groups of animals have improved their performance in the water maze. In contrast, at the end of the second week of training (i.e., in the Barnes maze), the D3-FITC groups of animals have slightly, but significantly, improved their performance whereas the control mice have not improved their performance. This, most likely, is related to the very large decrease in $A \beta$ load and plaque number in the hippocampus of the treated group of mice compared to the control group. Finally, the data suggest that no cognitive improvement is present after $6 \frac{1}{2}$ weeks of treatment (i.e., water maze testing), but that after $7 \frac{1}{2}$ weeks of treatment, a slight improvement is present. Together, the data indicate that either a longer treatment or a higher dose treatment in Tg AD model mice at this age with D3 or D3-FITC likely might be more beneficial. This is supported by the observation that plaque reduction was dependent on the distance from the infusion site, suggesting that the amount of D3-FITC that was infused was a limiting factor. This clearly raises the possibility that the binding of D3-FITC to oligomeric $A \beta_{42}$ significantly reduces synaptic pathology slowly, leading to a slow increase in cognitive abilities. D3FITC diffused or was transported throughout the brain, as suggested by the observed FITC-labeling of all dense plaques. Dependent of the distance from the infusion site, D3-FITC exerted different effects on the A $\beta$ load. It significantly reduced soluble and insoluble $\mathrm{A} \beta$ species, even in the contralateral brain hemisphere (Fig. 4). Dissolution of pre-existing plaques, however, was observed predominantly near the injection site. This suggests that higher D3-FITC concentrations, as can be expected close to the injection site, are required to dissolve pre-existing plaques during the treatment period of 8 weeks. Lower D3-FITC concentrations are still able to reduce soluble and insoluble $A \beta$ species throughout the brain. Because the plaque load reduction is restricted to the small area around the infusion site, the observed improvement of the cognitive behavior may be attributed much more to the reduction of soluble and insoluble $A \beta$ species than to any plaque dissolution. But because plaques are a reservoir for $\mathrm{A} \beta$ species, their disappearance may still be a valuable long term objective in any treatment. Treatment with D3 at higher concentrations and/or longer periods may well be suitable to achieve enhanced plaque clearance and even further reduced soluble and insoluble $\mathrm{A} \beta$ species.

This is a very important observation, because so far, most animal trials were designed to treat the $\mathrm{Tg}$ AD model animals at early stages, mostly before the appearance of deficits in cognitive behavior [12, 59]. Such trials might therefore be named more correctly prevention trials. This is currently heavily discussed as a major reason why substances that had been shown to be effective in such animal trials, later failed in clinical trials, which have yet been done with patients clearly diagnosed with $\mathrm{AD}$, thus being at progressed stages of the disease. Thus, after we had previously shown that D3 is efficient for treatment of young Tg AD mice by direct brain injection and oral application [26, 28], it was the main purpose of the present study to treat aged animals at progressed stages of pathology, when cognitive deficits had been present already for quite a while.

The data demonstrate that infusion with D3-FITC leads to a reduction in the density of $A \beta$ deposits in the hippocampus, whereas the infusion with the vehicle solution does not. Cognitive deficits are not significantly different between control and D3-FITC infused mice in the water maze test, but the D3-FITC infused mice do show a significant improvement on the last day of cognitive testing. Furthermore, the D3-FITC infused mice have a significant reduction in the number of plaques in the hippocampus, and in the amount of activated astrocytes and microglial cells surrounding $A \beta$ plaques compared to the control infused mice. Together, this demonstrates that this 
peptide has great potential as a future treatment in AD.

\section{ACKNOWLEDGMENTS}

We thank Dr. Egon von Schnier for his excellent comments on an earlier version of this manuscript. This study was partially supported by the Technology Transfer Fund of the Research Center Jülich and partially by NIH P30 NS47466.

Authors' disclosures available online (http://www.jalz.com/disclosures/view.php?id=1585).

\section{REFERENCES}

[1] Duyckaerts C, Delatour B, Potier MC (2009) Classification and basic pathology of Alzheimer disease. Acta Neuropathol 118, 5-36.

[2] Newell KL, Hyman BT, Growdon JH, Hedley-Whyte ET (1999) Application of the National Institute on Aging (NIA)Reagan Institute criteria for the neuropathological diagnosis of Alzheimer disease. J Neuropathol Exp Neurol 58, 11471155.

[3] Selkoe DJ (2001) Alzheimer's disease: Genes, proteins, and therapy. Physiol Rev 81, 741-766.

[4] Dickson TC, Vickers JC (2001) The morphological phenotype of beta-amyloid plaques and associated neuritic changes in Alzheimer's disease. Neuroscience 105, 99-107.

[5] Selkoe DJ, Wolfe MS (2007) Presenilin: Running with scissors in the membrane. Cell 131, 215-221.

[6] Van Broeck B, Van Broeckhoven C, Kumar-Singh S (2007) Current insights into molecular mechanisms of Alzheimer disease and their implications for therapeutic approaches. Neurodegener Dis 4, 349-365.

[7] Haass C, De Strooper B (1999) The presenilins in Alzheimer's disease-proteolysis holds the key. Science 286, 916-919.

[8] Kasuga K, Shimohata T, Nishimura A, Shiga A, Mizuguchi T, Tokunaga J, Ohno T, Miyashita A, Kuwano R, Matsumoto N, Onodera O, Nishizawa M, Ikeuchi T (2009) Identification of independent APP locus duplication in Japanese patients with early-onset Alzheimer disease. J Neurol Neurosurg Psychiatry 80, 1050-1052.

[9] Cabrejo L, Guyant-Marechal L, Laquerriere A, Vercelletto M, De la Fourniere F, Thomas-Anterion C, Verny C, Letournel F, Pasquier F, Vital A, Checler F, Frebourg T, Campion D, Hannequin D (2006) Phenotype associated with APP duplication in five families. Brain 129, 2966-2976.

[10] Rovelet-Lecrux A, Hannequin D, Raux G, Le Meur N, Laquerriere A, Vital A, Dumanchin C, Feuillette S, Brice A, Vercelletto M, Dubas F, Frebourg T, Campion D (2006) APP locus duplication causes autosomal dominant earlyonset Alzheimer disease with cerebral amyloid angiopathy. Nat Genet 38, 24-26.

[11] Guyant-Marechal L, Rovelet-Lecrux A, Goumidi L, Cousin E, Hannequin D, Raux G, Penet C, Ricard S, Mace S, Amouyel P, Deleuze JF, Frebourg T, Brice A, Lambert JC, Campion D (2007) Variations in the APP gene promoter region and risk of Alzheimer disease. Neurology 68, 684-687.

[12] German DC, Eisch AJ (2004) Mouse models of Alzheimer's disease: Insight into treatment. Rev Neurosci 15, 353-369.
[13] Jankowsky JL, Slunt HH, Ratovitski T, Jenkins NA, Copeland NG, Borchelt DR (2001) Co-expression of multiple transgenes in mouse CNS: A comparison of strategies. Biomol Eng 17, 157-165.

[14] van Groen T, Kiliaan AJ, Kadish I (2006) Deposition of mouse amyloid beta in human APP/PS1 double and single AD model transgenic mice. Neurobiol Dis 23, 653-662.

[15] Jankowsky JL, Savonenko A, Schilling G, Wang J, Xu G, Borchelt DR (2002) Transgenic mouse models of neurodegenerative disease: Opportunities for therapeutic development. Curr Neurol Neurosci Rep 2, 457-464.

[16] Savonenko A, $\mathrm{Xu}$ GM, Melnikova T, Morton JL, Gonzales V, Wong MP, Price DL, Tang F, Markowska AL, Borchelt DR (2005) Episodic-like memory deficits in the APPswe/PS1dE9 mouse model of Alzheimer's disease: Relationships to beta-amyloid deposition and neurotransmitter abnormalities. Neurobiol Dis 18, 602-617.

[17] Tanzi RE, Bertram L (2005) Twenty years of the Alzheimer's disease amyloid hypothesis: A genetic perspective. Cell 120, 545-555.

[18] Wang YJ, Zhou HD, Zhou XF (2006) Clearance of amyloid-beta in Alzheimer's disease: Progress, problems and perspectives. Drug Discov Today 11, 931-938.

[19] Masters CL, Beyreuther K (2006) Alzheimer's centennial legacy: Prospects for rational therapeutic intervention targeting the Abeta amyloid pathway. Brain 129, 2823-2839.

[20] Monaco S, Zanusso G, Mazzucco S, Rizzuto N (2006) Cerebral amyloidoses: Molecular pathways and therapeutic challenges. Curr Med Chem 13, 1903-1913.

[21] Jahan M, Nag S, Krasikova R, Weber U, Muhs A, Pfeifer A, Spenger C, Willbold D, Gulyas B, Halldin C (2012) Fluorine-18 labeling of three novel D-peptides by conjugation with $\mathrm{N}$-succinimidyl-4-[18F]fluorobenzoate and preliminary examination by postmortem whole-hemisphere human brain autoradiography. Nucl Med Biol 39, 315-323.

[22] Gulyas B, Spenger C, Beliczai Z, Gulya K, Kasa P, Jahan M, Jia Z, Weber U, Pfeifer A, Muhs A, Willbold D, Halldin C (2012) Distribution and binding of 18F-labeled and 125I-labeled analogues of ACI-80, a prospective molecular imaging biomarker of disease: A whole hemisphere post mortem autoradiography study in human brains obtained from Alzheimer's disease patients. Neurochem Int 60, 153-162.

[23] Funke SA, Liu H, Sehl T, Bartnik D, Brener O, Nagel-Steger L, Wiesehan K, Willbold D (2012) Identification and characterization of an abeta oligomer precipitating peptide that may be useful to explore gene therapeutic approaches to Alzheimer disease. Rejuvenation Res 15, 144-147.

[24] Funke SA, Bartnik D, Gluck JM, Piorkowska K, Wiesehan K, Weber U, Gulyas B, Halldin C, Pfeifer A, Spenger C, Muhs A, Willbold D (2012) Development of a small D-enantiomeric Alzheimer's amyloid-beta binding peptide ligand for future in vivo imaging applications. PLoS One 7, e41457.

[25] Funke SA, Willbold D (2012) Peptides for therapy and diagnosis of Alzheimer's disease. Curr Pharm Des 18, 755-767.

[26] Funke SA, van Groen T, Kadish I, Bartnik D, Nagel-Steger L, Brener O, Sehl T, Batra-Safferling R, Moriscot C, Schoehn G, Horn AH, Muller-Schiffmann A, Korth C, Sticht H, Willbold D (2010) Oral treatment with the D-enantiomeric peptide D3 improves the pathology and behavior of Alzheimer's disease transgenic mice. ACS Chem Neurosci 1, 639-648.

[27] Wiesehan K, Stohr J, Nagel-Steger L, van Groen T, Riesner D, Willbold D (2008) Inhibition of cytotoxicity and amyloid fibril formation by a D-amino acid peptide that specifically binds to Alzheimer's disease amyloid peptide. Protein Eng Des Sel 21, 241-246. 
[28] van Groen T, Wiesehan K, Funke SA, Kadish I, Nagel-Steger L, Willbold D (2008) Reduction of Alzheimer's disease amyloid plaque load in transgenic mice by D3, a D-enantiomeric peptide identified by mirror image phage display. ChemMedChem 3, 1848-1852.

[29] van Groen T, Kadish I, Funke A, Bartnik D, Willbold D (2012) Treatment with Abeta42 binding d-amino acid peptides reduce amyloid deposition and inflammation in APP/PS1 double transgenic mice. Adv Protein Chem Struct Biol 88, 133-152.

[30] van Groen T, Kadish I, Wiesehan K, Funke SA, Willbold $\mathrm{D}$ (2009) In vitro and in vivo staining characteristics of small, fluorescent, Abeta42-binding D-enantiomeric peptides in transgenic AD mouse models. ChemMedChem 4, 276-282.

[31] Franklin KBJ, Paxinos G (1997) The Mouse Brain in Stereotaxic Coordinates. Academic Press, New York.

[32] Barnes CA (1979) Memory deficits associated with senescence: A neurophysiological and behavioral study in the rat. J Comp Physiol Psychol 93, 74-104.

[33] Ida N, Hartmann T, Pantel J, Schroder J, Zerfass R, Forstl H, Sandbrink R, Masters CL, Beyreuther K (1996) Analysis of heterogeneous A4 peptides in human cerebrospinal fluid and blood by a newly developed sensitive Western blot assay. J Biol Chem 271, 22908-22914.

[34] Kadish I, Van Groen T (2002) Low levels of estrogen significantly diminish axonal sprouting after entorhinal cortex lesions in the mouse. $J$ Neurosci 22, 4095-4102.

[35] Liu L, Ikonen S, Tapiola T, Tanila H, van Groen T (2002) Fimbria-fornix lesion does not affect APP levels and amyloid deposition in the hippocampus of APP+PS1 double transgenic mice. Exp Neurol 177, 565-574.

[36] Braak H, Braak E (1991) Neuropathological stageing of Alzheimer-related changes. Acta Neuropathol 82, 239-259.

[37] Kumar-Singh S (2008) Cerebral amyloid angiopathy: Pathogenetic mechanisms and link to dense amyloid plaques. Genes Brain Behav 7(Suppl 1), 67-82.

[38] Bartolini M, Bertucci C, Bolognesi ML, Cavalli A, Melchiorre C, Andrisano V (2007) Insight into the kinetic of amyloid beta (1-42) peptide self-aggregation: Elucidation of inhibitors' mechanism of action. ChemBioChem 8, 21522161.

[39] Iijima K, Liu HP, Chiang AS, Hearn SA, Konsolaki M, Zhong Y (2004) Dissecting the pathological effects of human Abeta40 and Abeta42 in Drosophila: A potential model for Alzheimer's disease. Proc Natl Acad Sci U S A 101, 66236628

[40] Permanne B, Adessi C, Fraga S, Frossard MJ, Saborio GP, Soto C (2002) Are beta-sheet breaker peptides dissolving the therapeutic problem of Alzheimer's disease? J Neural Transm Suppl 62, 293-301.

[41] Permanne B, Adessi C, Saborio GP, Fraga S, Frossard MJ, Van Dorpe J, Dewachter I, Banks WA, Van Leuven F, Soto C (2002) Reduction of amyloid load and cerebral damage in a transgenic mouse model of Alzheimer's disease by treatment with a beta-sheet breaker peptide. FASEB J 16, 860-862.

[42] Soto C, Kindy MS, Baumann M, Frangione B (1996) Inhibition of Alzheimer's amyloidosis by peptides that prevent beta-sheet conformation. Biochem Biophys Res Commun 226, 672-680.

[43] Ji Y, Permanne B, Sigurdsson EM, Holtzman DM, Wisniewski T (2001) Amyloid beta40/42 clearance across the blood-brain barrier following intra-ventricular injections in wild-type, apoE knock-out and human apoE3 or E4 expressing transgenic mice. J Alzheimers Dis 3, 23-30.

[44] Tanzi RE, Moir RD, Wagner SL (2004) Clearance of Alzheimer's Abeta peptide: The many roads to perdition. Neuron 43, 605-608.

[45] Yoshiike Y, Chui DH, Akagi T, Tanaka N, Takashima A (2003) Specific compositions of amyloid-beta peptides as the determinant of toxic beta-aggregation. J Biol Chem $\mathbf{2 7 8}$, 23648-23655.

[46] Bondolfi L, Calhoun M, Ermini F, Kuhn HG, Wiederhold KH, Walker L, Staufenbiel M, Jucker M (2002) Amyloidassociated neuron loss and gliogenesis in the neocortex of amyloid precursor protein transgenic mice. J Neurosci 22 , 515-522.

[47] van Groen T, Kadish I (2005) Transgenic AD model mice, effects of potential anti-AD treatments on inflammation and pathology. Brain Res Brain Res Rev 48, 370-378.

[48] van Groen T, Miettinen P, Kadish I (2011) Transgenic AD model mice, effects of potential anti-AD treatments on inflammation, and pathology. J Alzheimers Dis 24, 301-313.

[49] Akiyama H, Barger S, Barnum S, Bradt B, Bauer J, Cole GM, Cooper NR, Eikelenboom P, Emmerling M, Fiebich BL, Finch CE, Frautschy S, Griffin WS, Hampel H, Hull M, Landreth G, Lue L, Mrak R, Mackenzie IR, McGeer PL, O'Banion MK, Pachter J, Pasinetti G, Plata-Salaman C, Rogers J, Rydel R, Shen Y, Streit W, Strohmeyer R, Tooyoma I, Van Muiswinkel FL, Veerhuis R, Walker D, Webster S, Wegrzyniak B, Wenk G, Wyss-Coray T (2000) Inflammation and Alzheimer's disease. Neurobiol Aging 21, 383-421.

[50] Combs CK (2009) Inflammation and microglia actions in Alzheimer's disease. J Neuroimmune Pharmacol 4, 380-388.

[51] Lee CY, Landreth GE (2010) The role of microglia in amyloid clearance from the AD brain. J Neural Transm 117, 949-960.

[52] Garcia-Alloza M, Ferrara BJ, Dodwell SA, Hickey GA, Hyman BT, Bacskai BJ (2007) A limited role for microglia in antibody mediated plaque clearance in APP mice. Neurobiol Dis 28, 286-292.

[53] Pluta R, Misicka A, Barcikowska M, Spisacka S, Lipkowski AW, Januszewski S (2000) Possible reverse transport of beta-amyloid peptide across the blood-brain barrier. Acta Neurochir Suppl 76, 73-77.

[54] Thanopoulou K, Fragkouli A, Stylianopoulou F, Georgopoulos S (2010) Scavenger receptor class B type I (SR-BI) regulates perivascular macrophages and modifies amyloid pathology in an Alzheimer mouse model. Proc Natl Acad Sci U S A 107, 20816-20821.

[55] Conde JR, Streit WJ (2006) Microglia in the aging brain J Neuropathol Exp Neurol 65, 199-203.

[56] Graeber MB, Streit WJ (2010) Microglia: Biology and pathology. Acta Neuropathol 119, 89-105.

[57] Hardy J (1992) An 'anatomical cascade hypothesis' for Alzheimer's disease. Trends Neurosci 15, 200-201.

[58] Malm TM, Iivonen H, Goldsteins G, Keksa-Goldsteine V, Ahtoniemi T, Kanninen K, Salminen A, Auriola S, Van Groen T, Tanila H, Koistinaho J (2007) Pyrrolidine dithiocarbamate activates Akt and improves spatial learning in APP/PS1 mice without affecting beta-amyloid burden. J Neurosci 27, 37123721.

[59] Howlett DR (2011) APP transgenic mice and their application to drug discovery. Histol Histopathol 26, 1611-1632. 